\title{
MODEL INTEGER PROGRAMMING UNTUK MENGOPTIMALKAN PERENCANAAN PRODUKSI DI UKM " $X$ "
}

\author{
Achmad Alfian \\ Program Studi Teknik Industri, Fakultas Sains \& Teknologi \\ Universitas Katolik Musi Charitas \\ J1. Bangau No.60, Palembang 30113 \\ e-mail: a_alfian@ukmc.ac.id; alfian60@gmail.com
}

\begin{abstract}
ABSTRAK
Model Integer programming (Model Programa Bilangan Bulat) merupakan metode matematika dalam mengalokasikan sumber daya yang terbatas untuk mencapai fungsi tujuan. Fungsi Tujuan dalam model ini ada 2, yaitu memaksimumkan keuntungan atau meminimumkan biaya. Penelitian ini dilakukan di UKM " $X$ " dengan tujuan untuk mendapatkan jumlah produksi optimal agar didapatkan keuntungan maksimal. Karena UKM " $X$ " masih berbentuk usaha kecil menengah, maka belum melakukan perhitungan untuk perencanaan produksi yang baik agar dicapai solusi untuk mendapatkan keuntungan yang maksimal. Variabel keputusan yang diteliti adalah X1= Almari A, X2 = Almari B, dan X3 = Almari $C$ dengan keuntungan masing-masing tiap produk adalah Rp.544.997,-,Rp.644.378,-, dan Rp.574.444,-. Hasil dari penelitian ini yang dilakukan dengan alat bantu software POM For Windows V3 menunjukkan bahwa produksi yang sebaiknya dilakukan oleh UKM " $X$ ” agar mendapatkan keuntungan maksimal adalah memproduksi Almari $A=28$ buah, Almari $B=16$ buah, dan Almari $C=27$ buah dengan keuntungan yang didapat sebesar Rp. 41.079.950,-.
\end{abstract}

Kata kunci: Model, Programa Bilangan Bulat, Variabel, Maksimal.

\begin{abstract}
Integer programming model is a mathematical method in allocating limited resources to achieve the objective function. The objective function in this model is 2, which is maximizing profits or minimizing costs. This research was conducted at UKM " $X$ " with the aim of getting the optimal amount of production in order to obtain maximum profit. Because SME " $X$ " is still in the form of small and medium businesses, it has not yet performed calculations for good production planning in order to achieve a solution to get maximum profit. The decision variables studied were $X 1=$ Cupboards $A, X 2=$ Cupboards $B$, and X3 = Cupboards $C$ with the advantages of each product being Rp.544,997, - Rp.644,378, - and Rp.574,444, -. The results of this study carried out with POM For Windows V3 software tools showed that the production that should be carried out by UKM " $X$ " in order to get the maximum profit was producing cupboards $A=28$ pieces, cupboards $B=16$ pieces, and cupboards $C=27$ pieces with a profit of Rp. 41,079,950.
\end{abstract}

Keywords: Model, Round Number Program, Variable, Maximum

\section{PENDAHULUAN}

Globalisasi diartikan sebagai proses dimana batas-batas suatu negara menjadi semakin sempit karena kemudahan interaksi antara negara baik berupa pertukaran informasi, perdagangan, teknologi, gaya hidup dan bentuk-bentuk interaksi yang lain [1]. Era globalisasi dengan persaingan yang ketat dan sulit, setiap perusahaan berlomba-lomba untuk menjadi yang terbaik di bidangnya dengan cara meningkatkan dan mengembangkan kinerja agar dapat mencapai efektifitas dan efisiensi dalam menjalankan produksi. Dalam dunia industri, perbandingan antara biaya produksi dengan harga jual sangat mempengaruhi daya saing di pasar. Biaya produksi sangat ditentukan oleh efisiensi dan perhitungan perbandingan input terhadap output dalam proses produksi [2].

Perencanaan produksi merupakan hal yang sangat penting bagi suatu usaha dalam menjalankan kegiatan produksi. Hal ini sangat dibutuhkan untuk mempertahankan eksistensi perusahaan dalam menghadapi persaingan yang semakin berat. Tujuan dari peningkatan efektifitas dan efisiensi dalam proses produksi adalah untuk mendapatkan keuntungan yang optimal dengan memanfaatkan sumber daya yang ada. Tentunya setiap 
perusahaan selalu ingin mendapat keuntungan optimal, termasuk juga UKM "X". Suatu usaha yang baik adalah dapat melakukan perencanaan produksi yang dapat digunakan saat harga mengalami fluktuasi. Ketika harga bahan fluktuasi di luar perkiraan perusahaan dapat menutupi kekurangan tersebut sehingga kontinuitas perusahaan dapat selalu dipertahankan.

UKM "X" merupakan industri mebel yang memproduksi berbagai macam produk seperti meja, kursi, dan Almari (Lampiran Gambar Produk). Bahan baku utama UKM "X" ini adalah kayu, maka harus dilakukan perencanaan produksi yang baik agar dapat memanfaatkan sumber daya yang ada. Karena UKM "X" masih berbentuk usaha kecil menengah, maka belum dilakukan perencanaan produksi yang baik agar dicapai solusi untuk mendapatkan keuntungan yang optimal. Pemecahan masalah yang berkaitan dengan optimasi menggunakan Model Integer Programming.

\section{TINJAUAN PUSTAKA \\ Programa Bilangan Bulat}

Linear Programming (LP) merupakan salah satu teknik optimisasi yang paling banyak digunakan dan salah satu yang paling efektif di lingkungan Pertamina [3]. Prosedur solusi aljabar yang paling banyak digunakan untuk masalah pemrograman linier disebut metode simpleks, yang dikembangkan oleh George Dantzig pada tahun 1947 [4]. Program linier sering digunakan dalam menyelesaikan problem alokasi sumber daya [5]. Menurut Aminudin [6], program linier merupakan suatu model matematika untuk mendapatkan alternatif penggunaan terbaik atas sumber-sumber yang tersedia. Menurut Sitinjak [7], metode yang dapat digunakan untuk mencari solusi dari model program linier terbagi menjadi 2, yaitu: Metode Grafik dan Metode Simpleks.

Dalam beberapa kasus, variabel keputusan harus bernilai bulat, misalnya jumlah mobil, jumlah rumah, dan jumlah almari. Untuk menyelesaikan kasus seperti ini model Programa Linier tidak dapat dipakai. Programa bilangan bulat atau integer programming (IP) adalah bentuk lain dari programa linier atau linier programming (LP) di mana asumsi divisibilitasnya melemah atau hilang sama sekali. Bentuk ini muncul karena dalam kenyataannya tidak semua variabel keputusan dapat berupa bilangan pecahan.

Misalnya, jika variabel keputusan yang dihadapi adalah jumlah produk yang harus diproduksi untuk mencapai keuntungan maksimal, maka jawaban 10/3 adalah sangat tidak mungkin karena kita tidak bisa memproduksi produk setengah-setengah.Dalam hal ini harus ditentukan, apakah akan menggunakan 3 atau 4 produk.

Menurut Siringoringo [8] pemograman Linear bilangan bulat terdiri dari Metode Branch and Bound (cabang dan batas) adalah salah satu metode untuk menghasilkan penyelesaian optimal pemrograman linear yang menghasilkan variabel-variabel keputusan bilangan bulat. Sebuah programa linear dengan persyaratan tambahan bahwa semua variabelnya merupakan bilangan bulat. Programa bilangan bulat dibutuhkan ketika keputusan harus dilakukan dalam bentuk bilangan bulat (bukan pecahan yang sering terjadi bila kita gunakan programa linear) [9]. Dalam masalah integer programming, jika model mengharapkan semua variabel basis bernilai integer (bulat positif atau nol), dinamakan pure (all) integer programming. Jika model hanya mengharapkan variabel-variabel tertentu bernilai integer, dinamakan mixed integer programming. Dan jika model hanya mengharapkan nilai nol atau satu untuk variabelnya, dinamakan zero one integer programming [10]. Model integer programming sebenarnya sama dengan model linear programming, dengan tambahan batasan variabelnya harus bilangan bulat/integer.

Terdapat 3 macam permasalahan dalam integer programming [11], yaitu:

a) Pemrograman bulat murni, yaitu kasus dimana semua variabel keputusan harus berupa bilangan bulat. 
b) Pemrograman bulat campuran, yaitu kasus dimana beberapa, tapi tidak semua, variabel keputusan harus berupa bilangan bulat.

c) Pemrograman bulat biner, kasus dengan permasalahan khusus dimana semua variabel keputusan harus bernilai 0 dan 1 .

Model dari integer programming sebagai berkut:

Maksimumkan $\sum_{j=1}^{n} c_{j} x_{j}$

Dengan kendala $, \sum_{j=1}^{n} a_{i j} x_{j}=b_{i}, i=1,2,3, \ldots, m$

$$
x_{j} \geq 0
$$

$\mathrm{x}_{\mathrm{j}}$ integer, untuk beberapa atau untuk semua $\mathrm{j}=1,2,3, \ldots, \mathrm{n}$

\section{Metode Pemecahan Programa Bilangan Bulat}

Adapun metode pemecahan programa bilangan bulat ada 3 macam [10]:

1) Metode Grafis. Metode ini sama seperti metode pemecahan dalam programa linier dalam bentuk grafis, namun dengan tambahan pembatas yakni variabel keputusan sebagian atau semua berupa bilangan bulat.

2) Metode Round Off. Metode ini memberikan cara konvensional atau kolot terhadap permasaahan programa bilangan bulat, yakni melakukan pembulatan (round off) terhadap solusi optimal bila dimungkinkan

3) Metode Branch-and-Bound. Metode ini dilakukan dengan mengibaratkan suatu permasalahan sebagai pohon (tree), kemudian permasalahan tersebut dibagi atau dibuat percabangan (branching) ke dalam subset yang lebih.

\section{METODE PENELITIAN}

Pendekatan pembulatan dari solusi nilai pecahan dari programa linier ini tetap memenuhi semua kendala dan menyimpang cukup jauh dari solusi bulat yang tepat. Model Integer programming (Gambar 1) merupakan teknik dari linier programming dengan tambahan persyaratan semua atau beberapa variabel bernilai bulat non-negatif.

1) Selesaikan LP dengan metode grafik atau simpleks biasa. Jika solusi optimalnya berbentuk bilangan bulat maka pemecahan tersebut juga merupakan pemecahan optimal untuk program bilangan bulat. Selesai.

2) Jika masih ada bilangan pecahan, buatlah 2 sub problem bilangan bulat yang baru dengan cara memperluas formulasi (model) sebelumnya dengan kendala $X_{j} \leq i_{1}$ atau kendala $\mathrm{X}_{\mathrm{j}} \geq \mathrm{i}_{2}$. Proses ini disebut pencabangan (branch).

3) Ulangi langkah 1 dan 2.

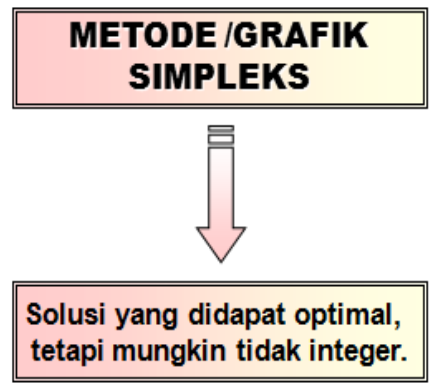

Gambar 1. Model Integer Programming 
Adapun beberapa langkah yang dilakukan dalam penelitian (Gambar 2) adalah sebagai berikut:

1) Studi Lapangan. Lokasi penelitian dilakukan di UKM " $X$ ".

2) Identifikasi Masalah. Permasalahan yang diidentifikasi dalam kegiatan penelitian ini adalah membuat model Integer Programming dari persoalaan yang dapat mempresentasikan sistem yang terjadi.

3) Merumuskan Tujuan Penelitian. Rumusan masalah dalam penelitian ini adalah mengetahui rencana produksi yang ada UKM " $X$ " dan bagaimana membuat model Integer Programming yang dapat mempresentasikan sistem yang terjadi.

4) Studi Pustaka. Studi pustaka diharapkan membantu penulis dalam menyelesaikan permasalahan dengan mengumpulkan berbagai teori dan konsep dari buku dan penelitian-penelitian yang sudah ada untuk dijadikan landasan berpikir.

5) Pengumpulan Data. Melakukan pengumpulan data jumlah kebutuhan bahan baku, jumlah persediaan langsung objek penelitian di tempat kerja dan lingkungan sekitar.

6) Membangun Model. Setelah mendapatkan informasi dan data-data didapat, maka dibangun model. Model yang telah dibangun akan memberikan abstraksi dengan elemen struktural dan operasi antar elemen yang membentuk sistem.

7) Menjalankan Program. Dalam tahap ini dilakukan serangkaian pengolahan data dengan bantuan menggunakan aplikasi POM For Windows V3.

8) Analisis. Data yang telah dikumpulkan dan diolah kemudian dianalisis untuk mengetahui jumlah rencana produksi, dan keuntungan yang didapat nantinya.

9) Kesimpulan. Isinya adalah jawaban dari apa yang menjadi permasalahan yang telah dirumuskan dalam rumusan masalah.

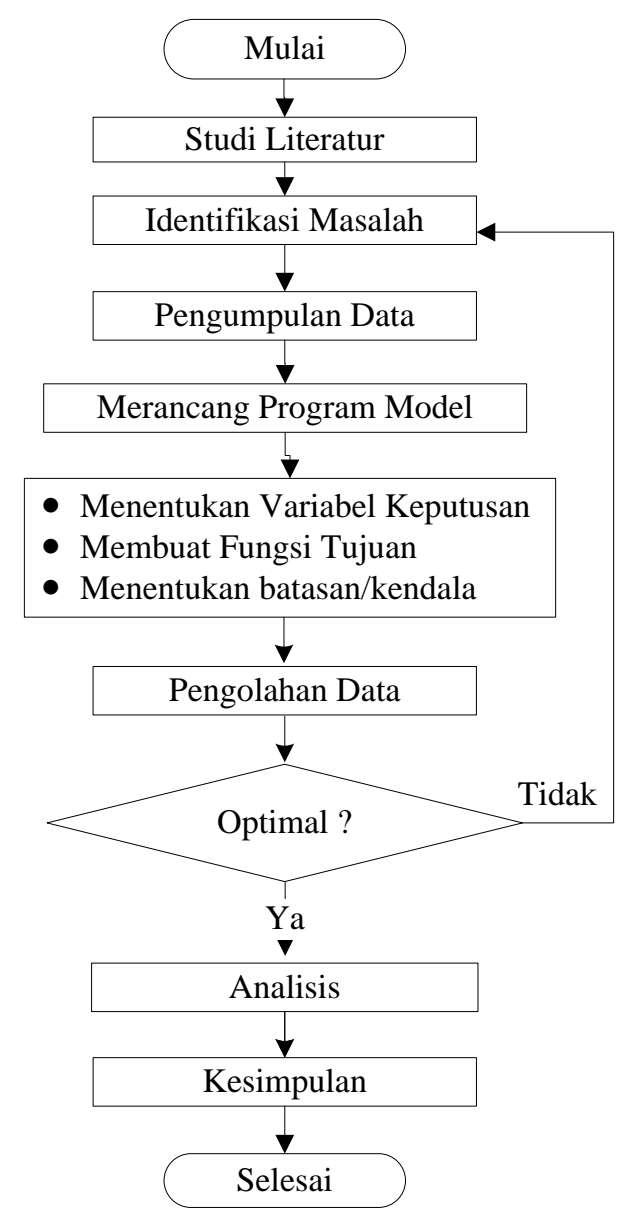

Gambar 2. Flowchart Metode Penelitian 


\section{HASIL DAN PEMBAHASAN}

\section{Hasil}

Data-data yang diperlukan selama penelitian, diantara data penjualan Tabel 1 , data persediaan Tabel 2, data kebutuhan bahan baku Tabel 3, biaya produksi Tabel 4, waktu produksi Tabel 5, dan keuntungan profit Tabel 6.

Tabel 1. Data Penjualan UKM "X"

\begin{tabular}{ccccc}
\hline \multirow{2}{*}{ Bulan } & \multicolumn{3}{c}{ Produk } & \multirow{2}{*}{ Jumlah } \\
\cline { 2 - 4 } & Almari A & Almari B & Almari C & \\
\hline 1 & 23 & 23 & 25 & 71 \\
2 & 25 & 21 & 18 & 64 \\
3 & 18 & 21 & 20 & 59 \\
4 & 29 & 19 & 20 & 68 \\
5 & 19 & 24 & 22 & 65 \\
6 & 22 & 21 & 19 & 62 \\
7 & 19 & 21 & 21 & 61 \\
8 & 21 & 22 & 19 & 62 \\
9 & 22 & 23 & 18 & 63 \\
10 & 20 & 22 & 21 & 63 \\
11 & 21 & 19 & 23 & 63 \\
12 & 24 & 20 & 27 & 71 \\
\hline Rata-rata & 21,92 & 21,33 & 21,08 & 64,33 \\
\hline Maksimum & 29 & 24 & 27 & 71 \\
\hline Minimum & 18 & 19 & 18 & 59 \\
\hline
\end{tabular}

Tabel 2. Data Persediaan Bahan Baku

\begin{tabular}{lcc}
\hline \multicolumn{1}{c}{ Bahan } & Persediaan & Harga (Rp) \\
\hline Kayu Akasia & $12 \mathrm{~m} 3$ & 1.800 .000 \\
Paku 1" & $25 \mathrm{~kg}$ & 16.000 \\
Paku 1,75" & $75 \mathrm{~kg}$ & 16.000 \\
Paku 3" & $25 \mathrm{~kg}$ & 16.000 \\
Engsel Piano 3,8 m (2 box) & $760 \mathrm{~m}$ & 3.158 \\
Kaki & $500 \mathrm{buah}$ & 2.750 \\
Kunci No 101 (20 Lusin) & $240 \mathrm{buah}$ & 2500 \\
Endel (40 Lusin) & $480 \mathrm{buah}$ & 1458 \\
Kaca 95 cm x 30 cm & $100 \mathrm{lembar}$ & 45000 \\
Amplas No 80 (4 Rol) & $200 \mathrm{~m}$ & 10000 \\
Lem Fox 850 gr (32 bks) & $27,2 \mathrm{~kg}$ & 18000 \\
Spritus & $40 \mathrm{~kg}$ & $15 / \mathrm{gr}$ \\
Sirlak Emping & $20 \mathrm{~kg}$ & $55 / \mathrm{gr}$ \\
Pernis & $30 \mathrm{ltr}$ & 45000 \\
Tiner Cobra & $15 \mathrm{ltr}$ & 29000 \\
\hline
\end{tabular}

Tabel 3. Data Kebutuhan Bahan Produksi

\begin{tabular}{|c|c|c|c|c|c|c|}
\hline Bahan & Almari A & Biaya (Rp) & Almari B & Biaya (Rp) & Almari C & Biaya $(\mathbf{R p})$ \\
\hline Kayu Akasia & 0,143 & 257.143 & 0,200 & 360.000 & 0,125 & 225.000 \\
\hline Paku 1" & 0,1 & 1.600 & 0,2 & 3.200 & 1 & 1.600 \\
\hline Paku 1,75" & 0,3 & 4.800 & 0,4 & 6.400 & 0,3 & 4.800 \\
\hline Paku 3” & 0,1 & 1.600 & 0,1 & 1.600 & 0,1 & 1.600 \\
\hline Engsel Piano $3,8 \mathrm{~m}$ (2 box) & 240 & 7.579 & 360 & 11.368 & 200 & 6.316 \\
\hline Kaki & 4 & 11.000 & 4 & 11.000 & 4 & 11.000 \\
\hline Kunci No 101 (20 Lusin) & 2 & 5.000 & 3 & 7.500 & 3 & 7.500 \\
\hline Endel (40 Lusin) & 4 & 5.833 & 6 & 8.750 & 5 & 7.292 \\
\hline Kaca $95 \mathrm{~cm}$ x $30 \mathrm{~cm}$ & 1 & 45.000 & 1 & 45.000 & 1 & 45.000 \\
\hline Amplas No 80 (4 Rol) & 2 & 20.000 & 3 & 30.000 & 2 & 20.000 \\
\hline Lem Fox 850 gr (32 bks) & 250 & 5.294 & 350 & 7.412 & 250 & 5.294 \\
\hline Spritus & 400 & 6.000 & 600 & 9.000 & 400 & 6.000 \\
\hline Sirlak Emping & 150 & 8.250 & 200 & 11.000 & 150 & 8.250 \\
\hline Pernis & 0,5 & 22.500 & 0,6 & 27.000 & 0,5 & 22.500 \\
\hline Tiner Cobra & 0,25 & 7.250 & 0,3 & 8.700 & 0,25 & 7.250 \\
\hline
\end{tabular}


Tabel 4. Total biaya produksi per bulan

\begin{tabular}{clc}
\hline No & Jenis biaya & Biaya/bulan (Rp) \\
\hline 1 & Bahan baku & 38.245 .000 \\
2 & Upah karyawan & 16.200 .000 \\
3 & Listrik & 1.000 .000 \\
\hline & Total & $\mathbf{5 5 . 4 4 5 . 0 0 0}$ \\
\hline
\end{tabular}

Tabel 5. Data Waktu Produksi

\begin{tabular}{lc}
\hline Produk & Lama Produksi (Jam) \\
\hline Almari A & 8 \\
Almari B & 10 \\
Almari C & 8 \\
\hline
\end{tabular}

Tabel 6. Keuntungan/Profit Per Produk

\begin{tabular}{cccccc}
\hline Produk & Harga Jual (Rp) & Biaya Bahan (Rp) & Upah (Rp) & Listrik (Rp) & Profit (Rp) \\
\hline Almari A & 1.200 .000 & 408.849 & 207.692 & 38.462 & 544.997 \\
Almari B & 1.500 .000 & 547.930 & 259.615 & 48.077 & 644.378 \\
Almari C & 1.200 .000 & 379.402 & 207.692 & 38.462 & 574.444 \\
\hline
\end{tabular}

\section{Pembahasan}

\section{Membuat Model}

Berdasarkan data yang diperoleh, maka langkah-langkah dalam memecahkan permasalahan tersebut adalah sebagai berikut:

1) Menentukan variabel keputusan:

$$
\begin{aligned}
& \mathrm{X}_{1}=\text { Almari A } \\
& \mathrm{X}_{2}=\text { Almari B } \\
& \mathrm{X}_{3}=\text { Almari C }
\end{aligned}
$$

2) Menentukan variabel keputusan:

Menentukan fungsi tujuan dari permasalahan tersebut. Koefisien fungsi tujuan merupakan keuntungan dari setiap produk yang dihasilkan (Almari A, Almari B, dan Almari C).

Maksimumkan:

$$
Z=544.997 X_{1}+644.378 X_{2}+574.444 X_{3}
$$

3) Menentukan batasan atau kendala-kendala dari permasalahan tersebut.

Kendala dalam permasalahan ini merupakan penggunaan bahan baku dan biaya produksi. Kendala-kendala dapat dituliskan sebagai berikut:

$\begin{array}{lllll}\text { Kayu } & : 0,14 \mathrm{X}_{1} & +0,2 \mathrm{X}_{2} & +0,125 \mathrm{X}_{3} & \leq 12 \\ \text { Engsel } & : 240 \mathrm{X}_{1} & +360 \mathrm{X}_{2} & +200 \mathrm{X}_{3} & \leq 76000 \\ \text { Waktu } & : 8 \mathrm{X}_{1} & +10 \mathrm{X}_{2} & +8 \mathrm{X}_{3} & \leq 600 \\ \text { Kaki } & : 4 \mathrm{X}_{1} & +4 \mathrm{X}_{2} & +4 \mathrm{X}_{3} & \leq 500 \\ \text { Kunci } & : 2 \mathrm{X}_{1} & +3 \mathrm{X}_{2} & +3 \mathrm{X}_{3} & \leq 240 \\ \text { Endel } & : 4 \mathrm{X}_{1} & +6 \mathrm{X}_{2} & +5 \mathrm{X}_{3} & \leq 480 \\ \text { Paku 1" } & : 0,1 \mathrm{X}_{1} & +0,2 \mathrm{X}_{2} & +0,1 \mathrm{X}_{3} & \leq 25 \\ \text { Paku 3" } & : 0,1 \mathrm{X}_{1} & +0,1 \mathrm{X}_{2} & +0,1 \mathrm{X}_{3} & \leq 25 \\ \text { Paku 1,75” } & : 0,3 \mathrm{X}_{1} & +0,4 \mathrm{X}_{2} & +0,3 \mathrm{X}_{3} & \leq 75 \\ \text { Kaca } & : 1 \mathrm{X}_{1} & +1 \mathrm{X}_{2} & +1 \mathrm{X}_{3} & \leq 100 \\ \text { Amplas } & : 2 \mathrm{X}_{1} & +3 \mathrm{X}_{2} & +2 \mathrm{X}_{3} & \leq 200 \\ \text { Lem } & : 250 \mathrm{X}_{1} & +350 \mathrm{X}_{2} & +250 \mathrm{X}_{3} & \leq 27.200 \\ \text { Spritus } & : 400 \mathrm{X}_{1} & +600 \mathrm{X}_{2} & +400 \mathrm{X}_{3} & \leq 40.000 \\ \text { Sirlak } & : 150 \mathrm{X}_{1} & +200 \mathrm{X}_{2} & +150 \mathrm{X}_{3} & \leq 20.000 \\ \text { Pernis } & : 0,5 \mathrm{X}_{1} & +0,6 \mathrm{X}_{2} & +0,5 \mathrm{X}_{3} & \leq 40 \\ \text { Tiner } & : 0,25 \mathrm{X}_{1} & +0,3 \mathrm{X}_{2} & +0,25 \mathrm{X}_{3} & \leq 20 \\ \text { Biaya } & : 655.003 \mathrm{X}_{1} & +855.622 \mathrm{X}_{2} & +625.556 \mathrm{X}_{3} & \leq 65.000 .000 \\ \text { Maks } \mathrm{X}_{1} & : \mathrm{X}_{1} & & & \leq 29 \\ \text { Maks X } & : & \mathrm{X}_{2} & & \end{array}$


4) Model di Program POM For Windows V3

\begin{tabular}{|c|c|c|c|c|c|c|}
\hline & $\mathrm{X} 1$ & $\mathrm{X} 2$ & $\mathrm{X} 3$ & & RHS & Equation form \\
\hline Maximize & 544997 & 644378 & 574444 & & & Max 544997X1+644378X2 + 574444X3 \\
\hline Engsel & 240 & 360 & 200 & $<=$ & 76000 & $240 X 1+360 X 2+200 X 3<=76000$ \\
\hline Kaki & 4 & 4 & 4 & $<=$ & 500 & $4 X 1+4 X 2+4 X 3<=500$ \\
\hline Kunci & 2 & 3 & 3 & $<=$ & 240 & $2 X 1+3 X 2+3 X 3<=240$ \\
\hline Endel & 4 & 6 & 5 & $<=$ & 480 & $4 X 1+6 \times 2+5 \times 3<=480$ \\
\hline Paku 1.75 & 0.3 & 0.4 & 0.3 & $<=$ & 75 & $.3 X 1+.4 X 2+.3 \times 3<=75$ \\
\hline Kaca & 1 & 1 & 1 & $<=$ & 100 & $\mathrm{X} 1+\mathrm{X} 2+\mathrm{X} 3<=100$ \\
\hline Amplas & 2 & 3 & 2 & $<=$ & 200 & $2 X 1+3 X 2+2 X 3<=200$ \\
\hline Lem & 250 & 350 & 250 & $<=$ & 27200 & $250 X 1+350 \times 2+250 \times 3<=27200$ \\
\hline Spritus & 400 & 600 & 400 & $<=$ & 40000 & $400 \times 1+600 \times 2+400 \times 3<=40000$ \\
\hline $\mathrm{X} 1$ & 1 & 0 & 0 & $<=$ & 29 & $X 1<=29$ \\
\hline $\mathrm{X} 2$ & 0 & 1 & 0 & $<=$ & 24 & $\mathrm{X} 2<=24$ \\
\hline $\mathrm{X} 3$ & 0 & 0 & 1 & $<=$ & 27 & $X 3<=27$ \\
\hline Variable type & Integer & Integer & Integer & & & \\
\hline
\end{tabular}

Tabel 7. Tabel Output

\begin{tabular}{ccc}
\hline Variable & Type & Value \\
\hline Almari $\mathrm{A}=\mathrm{X} 1$ & Integer & 28 \\
Almari $\mathrm{B}=\mathrm{X} 2$ & Integer & 16 \\
Almari $\mathrm{C}=\mathrm{X} 3$ & Integer & 27 \\
\hline Solution value & & 41079950 \\
\hline
\end{tabular}

Dari hasil pengolahan data menggunakan software POM For Windows V3 didapatkan hasil (Tabel 7), yaitu jika UKM Mebel "X" memproduksi Almari A (X1) = 28, Almari B $(X 2)=16$, Almari C $(X 3)=27$, dan keuntungan $(Z)=R p 41.079 .950,-$. karena: $\mathrm{Z}=\mathrm{Rp544.997}(28)+\mathrm{Rp} 644.378$ (16) + Rp574.444 (27) = Rp 41.079.950,-

\section{KESIMPULAN}

Berdasarkan hasil perhitungan dan pengolahan data bahwa rencana produksi yang optimal dari UKM mebel "X" yang di dapat sebagai berikut:

1) Dari perhitungan manual dengan software POM QM For Windows V3 diketahui bahwa produksi yang optimal adalah:

- Memproduksi Almari A (X1) = 29 unit

- Memproduksi Almari B (X2) = 16 unit

- Memproduksi Almari C (X3) = 27 unit

2) Berdasarkan kendala yang ada didapat keuntungan maksimal sebesar Rp 41.079.950,-

\section{DAFTAR PUSTAKA}

[1]. Nurhaidah, M. Insya Musa., 2016, Dampak Pengaruh Globalisasi Bagi Kehidupan Bangsa Indonesia, Jurnal Pesona Dasar, Vol. 3 No. 3, hal 1- 14.

[2]. Windarti, Tantri., 2013, Pemodelan Optimalisasi Produksi Untuk Memaksimalkan Keuntungan Dengan Menggunakan Metode Pemrograman Linier, Spektrum Industri, 11 (2): 117-242

[3]. Aji, Septi, Kusmaningrum, Fifi Herni M., 2014, Optimasi Keuntungan Menggunakan Linear Programming di PT Pertamina Refinery Unit (RU) VI Balongan, Jurnal Online Institut Teknologi Nasional, 03 (01).

[4]. Mulyono, Sri., 2017, Riset Operasi Edisi 2. Jakarta: Mitra Wacana Media.

[5]. Sitorus, Parlin., 1997, Program Linier. Universitas Trisakti, Jakarta. 
[6]. Aminudin, 2005, Prinsip-prinsip Riset Operasi. Jakarta:Erlangga.

[7]. Sitinjak, T. J. R., 2006, Riset Operasi: Untuk Pengambilan Keputusan Manajerial dengan Aplikasi Excel. Yogyakarta: Graha Ilmu.

[8]. Siringoringo, Hotnair., 2005, Seri Teknik Riset Operasi. Pemrograman Linear. Yogyakarta:Graha Ilmu.

[9]. Dimyati, Tjutju Tarliah, dan Ahmad Dimyati., 2010, Operations Research ModelModel Pengambilan Keputusan. Bandung: Sinar Baru Algesindo.

[10]. Hamdy A. Taha., 1996, Riset Operasi. Binarupa Aksara, Jakarta.

[11]. Hillier, F.S.and Lieberman, G.J., 1995, Introduction to Operation Research, Holden Day, Inc. USA. 


\section{LAMPIRAN GAMBAR PRODUK}

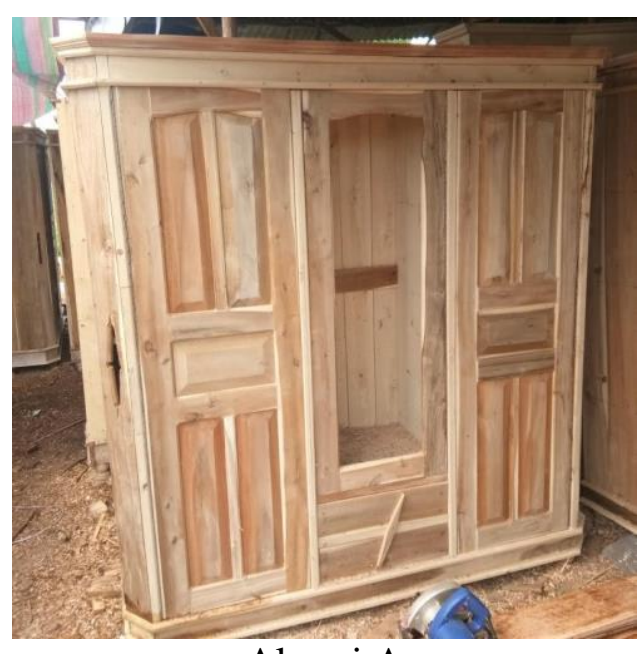

Almari A

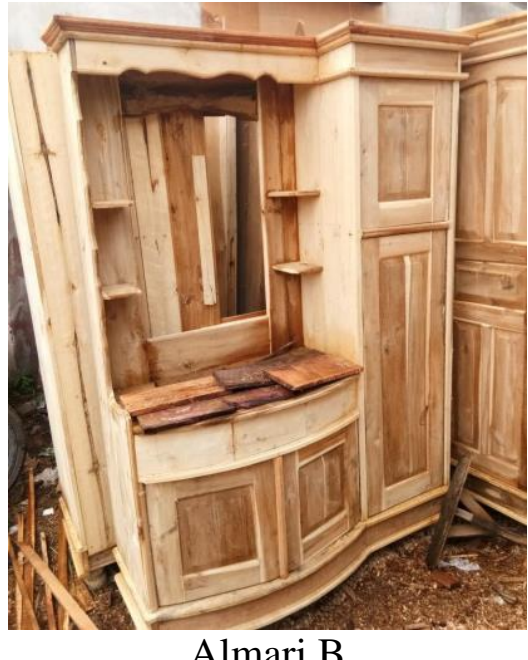

Almari B

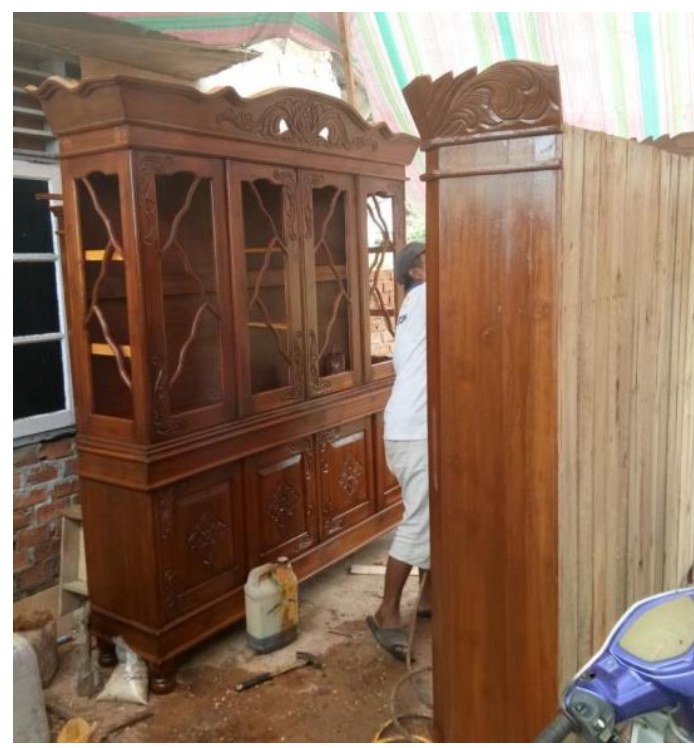

Almari C 